\title{
A língua como "tesouro" versus a resposta ativa do sujeito: o discurso da mídia impressa sobre a reforma ortográfica e implicações para o ensino de línguas
}

\section{Rita Maria Diniz ZozZoLI}

Doutora em Letras e Linguística pela Faculté des Lettres/Universidade de Franche-Comté/ França. Professora da Faculdade de Letras da Universidade Federal de Alagoas.

Parte deste texto foi apresentada no III Encontro de Ciências da Linguagem Aplicadas ao Ensino (ECLAE), em Maceió, de 5 a 7 de dezembro de 2007.

Resumo: O presente trabalho defende a ideia de que a profusão de artigos de jornais e revistas brasileiros sobre a reforma ortográfica da língua portuguesa em processo de implantação responde a objetivos de instâncias de poder que determinam a língua considerada legítima, apresentando argumentos que vão repercutir na visão de língua do senso comum, nas práticas de formação docente e no ensino da língua portuguesa. Contrapondo-se a essas instâncias de poder, uma perspectiva de resposta ativa (BAKHTINE*'NOLOSCHINOV, 1977; BAKHTINE, 1975; BAKHTIN, 2003) do sujeito pode apontar caminhos para o trabalho efetuado com a língua em diversos contextos de ensino.

Palavras-chave: discurso; mídia impressa; resposta ativa, ensino do português
Résumé: Ce texte défend lidée suivant laquelle la profusion d'articles de la presse brésilienne sur la réforme orthographique de la langue portugaise en voie dimplantation répond à des objectifs dinstances de pouvoir qui déterminent la langue devant être considérée légitime, en se valant d' arguments qui se répercutent sur la notion de langue du sens comun, sur les pratiques de formation des professeurs et sur l'enseignement de la langue portugaise. En opposition aux forces de ces instances de pouvoir, une perspective de réponse active (BAKHTINE/ VOLOSCHINOV, 1977; BAKHTINE, 1975; BAKHTIN, 2003) du sujet peut montrer d'autres voies pour l'enseignement de la langue dans différents contextes.

Mots-clés: discours; presse écrite; réponse active; enseignement du portugais

* Para respeitar a ficha bibliográfica dos livros consultados, são utilizadas neste texto as duas grafias: Bakhtin, Mikhail, para as obras em português, e Bakhtine, Mikhaïl, para as obras em francês. 

A questão da preservação/destruição das línguas e culturas não se resume a uma dimensão pontual, limitada no tempo e no espaço por determinadas medidas empreendidas pelos mecanismos de poder a quem cabem essas condutas. Pelo contrário, a elaboração de reformas e discussões decorrentes dessas ações enquadra-se numa perspectiva histórica cujas origens sociais e políticas remontam aos primórdios da civilização humana e, no caso particular examinado neste artigo, à criação das nações ditas ocidentais.

Eco (2001) afirma que a multiplicidade/unificação das línguas sempre foi tema que perpassou a história de todas as culturas e, atendo-se mais às culturas europeias, percebe, por exemplo, na confusão babélica apresentada na Bíblia e na leitura da Torá pela cabala, o sonho humano de uma língua perfeita/universal. A "diferenciação natural" das línguas seria ponto negativo ou positivo de acordo com as épocas, as filosofias, as teorias, bem como a tese do monolinguismo ou a do polilinguismo originários também foi e ainda é matéria de discussão entre filósofos e outros estudiosos de diferentes áreas.

\section{Desejo da unificação simbólica aliado a políticas de dominação}

Em outro trabalho (ZOZZOLI, 2002), distingo duas tensões que se contrapõem na história das nações ditas ocidentais, suas línguas e suas culturas: uma, da dominação da língua materna (aqui entendida como nacional/oficial/dominante) e de sua cultura, correspondendo ao ideal monolíngue mencionado por Achard (1989) e ao ideal mítico da homogeneidade nacional definido por Decrosse (1989) (o que corresponde, neste trabalho, à utopia de uma língua perfeita, segundo Eco, 2001); outra, da dominação da língua tida como estrangeira e de sua cultura, exercida pelos invasores e colonizadores de todos os tipos.

Tratarei neste texto da primeira tensão, cujo objetivo de homogeneização envolve a questão dos acordos 
linguísticos entre países que falam uma determinada língua dominante.

Numa primeira reflexão, ao desejo da unificação simbólica presente na tese de Eco, percebo que é possível articular as razões políticas de dominação apresentadas por Certeau, Julia e Revel (1975) no processo de instituição de uma língua nacional. Esses autores mostram, através do exemplo da língua francesa, como se deu/se dá a destruição das culturas periféricas pela imposição sistemática das línguas oficiais pelo Estado no contexto europeu.

No diz respeito aos países colonizados, a entrevista feita pela jornalista Bergel, na revista Língua Portuguesa, com Xavier (2007, p. 38-41), assessor do atual ministro brasileiro da Educação, Haddad, nos traz o seguinte comentário do entrevistado:

Pois foram os portugueses que "inventaram o mundo" com as viagens marítimas e com as descobertas. Foi assim que o mundo se reconheceu como mundo: falando Português. Só a língua portuguesa, e não o Caiapó, não o Txucarramãe, não o Guarani e não o Ianomami ou as mais de 220 línguas faladas pelos índios do Brasil de hoje; e não as diversas línguas faladas pelos povos nativos de Angola. Só o português que circula pelo mundo, usando a mesma norma ortográfica, será capaz de traduzir e dizer o que é sermos um caiapó, como é o se sentir txucarramãe; o que é a vida dos guarani que moram no Sul do Brasil ou como se ama quando somos um ianomâmi [...] Ao contrário de prejudicar, a unificação da ortografia vai permitir o reforço das identidades nacionais e da diversidade cultural de cada país; vai propiciar a valorização das diferenças e da convivência.

Para mim, com esse argumento,
contraditoriamente, propõe-se contemplar as
diferenças através de uma unificação que as apaga.
Para serem compreendidas pelo mundo, as línguas e


culturas periféricas devem assujeitar-se a um processo de tradução, que aparentemente é apenas linguístico, mas que se revela simbólico: os diferentes devem subordinar-se ao padrão dominante, ser traduzidos por ele, para poder ser reconhecidos e continuar existindo. Assim, ao afirmar "só o português [...] será capaz de traduzir e dizer o que é sermos um caiapó” exclui-se a possibilidade de um caiapó dizê-lo em sua própria língua/cultura.

Nesse processo, a subordinação de línguas e culturas a padrões considerados legítimos, como única forma de subsistência, não se limita ao plano linguístico; ao mesmo tempo, restringem-se também as condições políticas e sociais necessárias à preservação das comunidades "periféricas".

O mesmo argumento é utilizado para explicar a necessidade de variedades do português serem também "traduzidas" pelo português padrão como única forma de subsistência. Essa é a perspectiva do ensino normativo existente numa grande parte de instituições de ensino em nosso país e, segundo Bourdieu (1996), o sistema de ensino cumpre um papel determinante na inculcação dessa língua legítima.

\section{Ensino e aprendizagem de padrões cultos nas instituições de ensino?}

Nesse ponto, é útil esclarecer que, ao discordar da submissão de uma língua a outra ou da submissão de padrões populares a "padrões cultos"1 como forma de subsistência, não pretendo defender a tese que considero extremista, segundo a qual é possível se ignorar padrões cultos e seu valor no mercado simbólico (expressão de Bourdieu, 1996) e que na escola não deveríamos sequer pretender considerá-los, sob pena de favorecer a dominação. Pretendo que é dever da escola reconhecer e respeitar todas as diferenças, linguísticas ou não. Mas é também dever da escola proporcionar o acesso a padrões cultos e à sua utilização, como forma de contribuir para a contraposição a essa dominação.
1 Prefiro falar em "padrões cultos", por não defender a ideia de que é possível identificar de alguma forma uma língua padrão idealizada e uniformizada e de trabalhar na prática com esse objeto mítico. 
Para Bourdieu (1996, p. 53), "os discursos não são apenas (a não ser excepcionalmente) signos destinados a serem compreendidos, decifrados; são também signos de riqueza [grifo do autor] a serem avaliados, apreciados, e signos de autoridade [grifo do autor] a serem acreditados e obedecidos".

Considero que negar essa relação de forças, tentando agir como se tudo fosse igual, seja através da subordinação a um padrão culto, seja para desconhecêlo, não permite que a instituição de ensino contribua para o acesso do cidadão/cidadã aos recursos linguísticodiscursivos que se transformam em bens simbólicos.

O desafio que se apresenta à instituição de ensino é de saber como atuar concretamente de forma a proporcionar conhecimentos sobre a diversidade linguística, sem impor uma língua oficial/dominante em detrimento de línguas ou de variedades de língua não reconhecidas. Em outros termos, trata-se de proporcionar ao aluno o conhecimento desse jogo de forças que não se concretizam apenas no plano linguístico.

No que diz respeito à gramática, o cerne da questão está em procurar abordá-la em função de condições de produção que se estabelecem na produção dos textos, em sala de aula ou fora dela, levando, portanto, em conta a existência de regras que se situam tanto no plano linguístico como no plano discursivo. Assim, revendo o que já afirmei em texto anterior (ZOZZOLI, 1999), nessa visão de gramática são considerados fenômenos de língua desde os menores (plano micro) até aqueles ligados a fenômenos do discurso (plano macro, que remete tanto às condições de produção imediatas como a uma dimensão mais ampla relacionada ao social e ao histórico).

Dito de outra forma, a adequação ou inadequação de determinado enunciado só poderá ser discutida dentro de condições de produção explícitas e suficientemente definidas, mesmo que sejam "fabricadas" (produzidas apenas para ações de sala de aula e sem previsão de extensão para fora dela). Por exemplo, são as condições de produção que vão determinar se um $e$-mail vai seguir um padrão 
convencional ou um padrão coloquial. Essa definição de padrão vai por sua vez determinar o uso de abreviações ou não; o uso de termos de um registro familiar ou não, assim como outras questões no plano micro.

\section{As políticas de unificação e os interesses do mercado global}

De acordo como que já foi discutido, as políticas de unificação de uma língua responsável por várias identidades nacionais, que seria, portanto, uma língua supranacional, atendem a políticas de dominação de um mercado globalizado (ou seja, ao interesse de grupos dominantes desse mercado), num plano nacional e supranacional. Para atender aos objetivos desse mercado, legitima-se a necessidade de acordos ortográficos entre países que falam a mesma língua.

A esse respeito, a profusão de artigos de jornais e revistas brasileiros, veiculados principalmente no segundo semestre de 2007, sobre o último acordo ortográfico da língua portuguesachamaaatençãoparaessa necessidadeglobalizante do mercado linguístico (não dissociado dos outros mercados, evidentemente) e permite analisar o acontecimento para além da questão estritamente linguística.

Para refletir melhor sobre o tema, parece-me útil primeiramente apresentar informações básicas sobre o acordo citado.

O referido acordo foi aprovado em Lisboa, em 12 de outubro de 1990, pela Academia das Ciências de Lisboa, Academia Brasileira de Letras e delegações de Angola, Cabo Verde, Guiné-Bissau, Moçambique e São Tomé e Príncipe, com a adesão da delegação de observadores da Galiza². Em 2004 tem-se a adesão de Timor, segundo o Portal da Língua Portuguesa. Pretende-se com ele promover "a unidade e o prestígio"3 $\mathrm{da}$ língua portuguesa nos países que a falam.

Prevista para entrar em vigor até $1^{\circ}$ de janeiro de $1994^{4}$, a "ortografia unificada" tem dificuldades em ser implantada: dos países citados, apenas o Brasil, Cabo Verde e São Tomé e Príncipe já ratificaram o acordo.
${ }^{2}$ Informação retirada do sítio Comunidade dos países de língua portuguesa.

${ }^{3}$ Termos extraídos do próprio texto do acordo.

4 Até $1^{\circ}$ de janeiro de 1993 é o prazo para a elaboração de "um vocabulário ortográfico comum da língua portuguesa, tão completo quanto desejável e tão normatizador quanto possível". 
Voltando ao foco de nosso trabalho, pergunto, então: como esse acordo que ainda não foi assinado por todos os países e que não é de grande amplitude, a julgarse pelos itens contemplados no texto da reforma, é capaz de fazer render muitos artigos, debates e outros gêneros de textos, incluindo imprensa falada, escrita e internet, bem antes de sua implantação?

Antes de tentar refletir sobre a questão, é útil esclarecer que não é meu objetivo examinar aqui a perspectiva estritamente linguística dos itens contemplados ou não pela reforma e que pretendo me ater às reflexões sobre o discurso da reforma ortográfica em textos da mídia jornalística e sua provável repercussão no ensino da língua materna, como já foi explicitado no início deste artigo.

\section{Análise de um exemplo da mídia impressa}

Como não é possível dar conta da amplitude do tema em um texto desta natureza, vou focalizar, portanto, mais especificamente a edição da Veja de 12 de setembro de 2007 que traz já na capa elementos que incitam os leitores a se preocupar não apenas com a reforma ortográfica, mas com a adequação à chamada norma culta. Tal posição será retomada na rubrica "Especial", com o título "Riqueza da língua" (TEIXEIRA, 2007, p. 88-96), e ainda no artigo "Restaurar é preciso; reformar não é preciso” (AZEVEDO, 2007, p. 98-99).

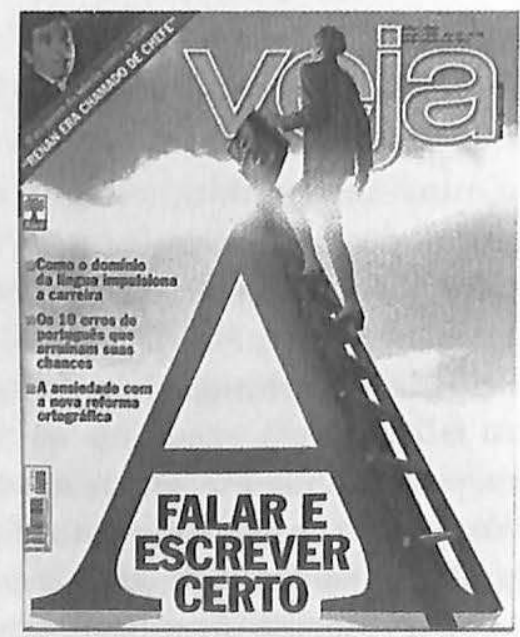


Antes de qualquer consideração, é necessário justificar que a análise da imagem se faz necessária porque ela constitui um signo ideológico, tal como o signo verbal. Para Bakhtine/Volochinov (1977, p. 33), os signos ideológicos, como uma representação pictural, por exemplo, apesar de não serem substituíveis por palavras, estão nelas apoiados, da mesma forma que "o canto é acompanhado pela música"5. Ainda segundo os mesmos autores (1977, p. 33), "Todas as manifestações da criação ideológica, todos os signos não verbais, banham-se no discurso e não podem ser nem inteiramente isoladas nem inteiramente separadas dele"6.

Assim, analisando a imagem, percebo que a escada da ascensão profissional apoia-se na letra "A", que parece reforçar a ideia de ascensão (não apenas por ser a primeira letra da palavra, mas também pela própria forma da letra, que se presta para apoio da escada). É interessante ver que o céu é o limite.

$\mathrm{Na}$ escada, apresenta-se uma executiva com físico e indumentárias contemporâneas. Eu a vejo, ao mesmo tempo, como figura andrógina, porque formas do corpo, cabelos e indumentária parecem moldados para essa visão, excetuando a saia e o sapato de salto, que são toques femininos discretos (o salto do sapato não é alto e a saia tem modelo sóbrio, "neutro"). No meio do corpo, nuvens disfarçam a transição entre a parte de baixo (mais feminina) e a parte de cima (mais neutra, com tendência masculina). A posição do tronco esconde os seios e faz prevalecer a silhueta masculina no tronco. Os cabelos curtos, com tendência mais masculina no corte (ver a zona das têmporas e das orelhas), e a ausência da face contribuem mais ainda para a ambiguidade entre masculino e feminino.

Dessa forma, é possível ${ }^{7}$ que essa personagem identifique o/a executivo/a contemporâneo/a. A essa representação pode estar subjacente também a ideia de um modelo de executivo/a, generalizante, modelar, da mesma forma que se defende um modelo de fala e de escrita.
${ }^{5}$ Todas as traduções dos textos em francês são de minha autoria.

${ }^{6} \mathrm{Na}$ tradução francesa, como na brasileira, "isoladas" e "separadas" encontram-se no feminino.

7 Trata-se de uma das interpretações possíveis, evidentemente. 
Na base da escada, em letras capitais, o tema principal da revista: FALAR E ESCREVER CERTO. E ao lado, sob a forma de links, as "chamadas": "Como o domínio da língua impulsiona a carreira"; "Os 10 erros de português que arruínam suas chances"; "A ansiedade com a nova reforma ortográfica".

É perceptível que a reforma surge em último lugar e que o discurso se apoia muito mais na necessidade de "falar e escrever certo para subir na carreira". A reforma, na verdade, é pretexto para veicular essa ideia, aliás inúmeras vezes repetida no texto intitulado "A riqueza da língua" (TEIXEIRA, 2007). Minha compreensão é que toda a agitação midiática em torno da reforma cumpre uma função ideológica subliminar: quem não fala nem escreve "certo" não tem chance. Esse "certo" será, conforme se afirma reiteradas vezes no texto citado, objeto de avaliação na carreira, como exemplificam os enunciados: "Dominar a norma culta de um idioma é plataforma de sucesso para profissionais de todas as áreas" (TEIXEIRA, 2007, p. 88); "A diferença entre um sucesso e um vexame pode ser determinada por uma simples crase mal utilizada" (TEIXEIRA, 2007, p. 89).

Subjaz aí, portanto, a visão de língua como "tesouro universal”, ideia que, segundo Bourdieu (1996), já estava presente em August Comte e é retomada por Saussure e por Chomsky, de formas diferentes:

- August Comte: "a linguagem institui naturalmente uma plena comunidade onde todos, haurindo livremente do tesouro universal, concorrem espontaneamente para sua conservação";

- Saussure: "tesouro depositado pela prática fala nos sujeitos pertencentes à mesma comunidade";

- Chomsky: "locutor-ouvinte ideal, inserido numa comunidade lingüística completamente homogênea, que conhece perfeitamente sua língua" (BOURDIEU, 1996, p. 29-30).

Comentário semelhante já tinha sido feito por Bakhtine/Voloschinov (1977, p. 107), quando esses 
autores afirmam que o objetivismo abstrato tem raízes no racionalismo dos séculos XVII e XVIII e tem continuidade nas idéias de Saussure e de seus discípulos (evidentemente Bakhtine/Voloschinov não poderiam ter falado na contemporaneidade no que diz respeito à gramática universal de Chomsky), concebendo a língua como produto acabado, que se transmite de geração a geração e a colocando fora do fluxo da comunicação verbal.

Portanto, a ideia de "tesouro" está presente na segunda orientação de pensamento definida e criticada por Bakhtine/Voloschinov, bem como na perspectiva dos puristas, se bem que de formas distintas. Para os puristas, trata-se de se defender a língua legítima, oficial dos patoás e das "deturpações" de todas as origens.

A respeito da noção de língua oficial, Bourdieu (1996, p. 31) afirma:

Produzida por autores com autoridade para escrever, fixada e codificada pelos gramáticos e professores, também incumbidos de inculcar seu manejo, a língua é um código, no sentido de cifra que permite estabelecer equivalências entre sons e sentidos, mas também na acepção de sistema de normas que regem as práticas lingüísticas.

Como já afirmei, com apoio em Bourdieu (1996), essa concepção de língua oficial se articula, ao mesmo tempo, ao discurso que defende o ideal de uma língua pura e unificada, geralmente a língua do colonizador e/ou dos interesses econômicos dominantes globalizantes ou não, mesmo que essa língua padrão permaneça uma entidade abstrata e pouco apreensível pelos próprios instrumentos que se propõem estudá-la.

Essa dominação recorre a estratégias de utilização do discurso autorizado sobre a questão da pureza da língua, de forma que esse discurso argumente em seu favor. Por exemplo, o único linguista citado no texto "A riqueza da língua", David Crystal, deixa claro que a "sobrevivência" de línguas se dá por uma "série de práticas políticas e 
econômicas que valorizam a diversidade" e que os estrangeirismos não são capazes de "destruir uma língua". No entanto, Crystal tem seu discurso apresentado como um apêndice e utilizado, na minha leitura, para apoiar a visão alarmista da extinção das línguas, que corresponde à tese do declínio das línguas da Linguística Histórica do século XIX (para Bopp, o estado antigo de uma palavra seria a "verdade gramatical do estado novo") (DUCROT; SHAEFFER, 1995, p. 28). Essa tese se opõe à ideia de Crystal, expressa no texto da entrevista, segundo a qual a incorporação de palavras estrangeiras "torna uma língua expressiva e rica". Mas no texto maior, conclui-se uma referência a Crystal, afirmando: "Cresce a consciência de que as línguas bem faladas, protegidas por normas cultas, são ferramentas da cultura e também armas da política, além de ser riquezas econômicas." (TEIXEIRA, 2007 , p. 89)

É nessa perspectiva que se insere o "falar e escrever certo", legitimando-se, ainda, pelo mesmo movimento, as práticas que distinguem, no âmbito do ensino e da avaliação (concursos e outros instrumentos diversos de avaliação), a seleção dos incluídos, a quem será destinado o "lucro de distinção" (BOURDIEU, 1996, p. 42 ).

Fora do contexto educacional, os enunciados proferidos em diversas instâncias de comunicação contribuem para "tecer milhares de fios dialógicos vivos" (BAKHTINE, 1975, p. 100), em torno da questão. Assim, textos escritos e orais em diversos veículos de comunicação dialogam entre si para concordar ou discordar dessa ideia de língua como tesouro.

O consenso das classes letradas em torno da visão de língua pura e unificada como tesouro é observável em textos de diferentes gêneros, na oralidade e na escrita, nas vozes de diferentes autoridades, dentre as quais o ex-presidente Fernando Henrique Cardoso, em discurso recente no fechamento do Congresso Nacional do PSDB:

Nosso partido tem gente acadêmica, não temos vergonha disso. Tem gente que sabe falar mais 
de uma língua, e também sabemos muito bem falar a nossa língua. Muitos brasileiros ainda não puderam saber falar bem a nossa língua e muito menos as outras (NAVARRO; SELIGMAN; RABELLO, 2007, Folha de S. Paulo, Caderno A6 ).

"Falar bem a nossa língua" parece se relacionar com o fato de ter "gente acadêmica", o que permite pensar em uma visão que atribui "o lucro da distinção" acima referido a uma determinada classe social que tem acesso ao "tesouro" da língua chamada culta.

Retomando o texto da revista Veja, observo que nele ainda se relaciona o falar e escrever certo à "riqueza vocabular": "Diversas pesquisas estabelecem correlações entre tamanho de vocabulário ${ }^{8}$ e habilidade de comunicação, de um lado, e ascensão profissional e ganho salariais, de outro" (TEIXEIRA, 2007, p. 89). Em outro trecho, fala-se de "um estudo feito em 39 empresas americanas", mas é interessante notar que as pesquisas não são nomeadas e tampouco os pesquisadores e os financiamentos que receberam. Observe-se que a tese da "riqueza vocabular" corresponde à visão de enquetes estatísticas realizadas na década de 50 , visando a estabelecer o conteúdo linguístico de um ensino de línguas a partir do critério de "freqüência de emprego" (GALISSON; COSTE, 1976). Essa tese, que fundamentou boa parte do ensino de línguas até a década de 70, não considera o discurso e suas condições de produção e, por esse motivo, não dá conta das inúmeras facetas e nuances que envolvem o emprego de uma palavra, inclusive os não-ditos.

Entretanto, para Bakhtine/Voloschinov, "o sentido da palavra é totalmente determinado por seu contexto. De fato, há tantas significações possíveis quanto contextos possíveis" (BAKHTINE/VOLOSCHINOV, 1977, p. 115). Além disso, a palavra, fenômeno ideológico por excelência, "acompanha e comenta todo ato ideológico" (1977, p.33). Os mesmos autores acrescentam: "Assim, o elemento que faz da forma lingüística um signo não é sua identidade como
${ }^{8}$ A matéria jornalística citada apresenta ainda, para apoiar suas ideias nesse sentido, uma pirâmide invertida que relaciona cargos em empresas ao "domínio de vocabulário" em termos quantitativos ( $\mathrm{p}$. 88-89). 
sinal, mas sua mutabilidade específica [...]" (1977, p. 101). Por esse prisma, formas estatisticamente repertoriadas só fazem reforçar o fator de reconhecimento de formas isoladas no ensino de línguas.

Práticas que empregam esses resultados estatísticos apostam na ideia de que memorizar os números, os dias da semana e outras listas faria com que o sujeito avançasse em sua aprendizagem da língua estrangeira. No caso da língua materna, o estudo de vocabulário do texto, identificando palavras e definições correspondentes, é realizado como proposta para acesso à "riqueza vocabular", como se essa "riqueza" enciclopédica tivesse o poder mágico de proporcionar "o desempenho lingüístico ideal".

Contrariamente a essa visão, ainda segundo Bakhtine/Voloschinov (1977, p. 101), a "assimilação ideal de uma língua" se dá quando o sinal é absorvido pelo signo e a identificação pela compreensão, porque é a compreensão recíproca que participa da formação do discurso: "Todo ato de comunicação é uma resposta, na medida em que ele introduz o objeto da compreensão num novo contexto potencial de resposta" (BAKHTINE/ VOLOSCHINOV,1977, p. 101).

Esse pensamento é reiterado mais uma vez por Bakhtin (2003, p. 271), quando afirma:

Toda compreensão da fala viva, do enunciado vivo é de natureza ativamente responsiva (embora o grau desse ativismo seja bastante diverso); toda compreensão é prenhe de resposta, e nessa ou naquela forma a gera obrigatoriamente: o ouvinte se torna falante.

Nos exemplos analisados, a ideologia da língua ideal, homogênea, "produto normatizado" (BOURDIEU, 1996), supõe um "público marcado e sem papel histórico" (CERTEAU, 1996, p. 262), opondo-se à visão de que a palavra "é o produto da interação entre o locutor e o ouvinte" (BAKHTINE/VOLOCHINOV, 1977, p. 123). As instâncias de poder que determinam essa língua legítima 
aproveitam a oportunidade de divulgação da citada reforma - que, aliás, uma grande parte dos estudiosos da própria norma culta reconhece de pouca interferência concreta na fala e na escrita da língua portuguesa como um todo - para reforçar a dominação exercida pelas classes dos que se servem da visão de língua pura: extraem a palavra da instância da enunciação (o falante da língua é julgado pelo número de palavras que conhece, por exemplo), apresentando argumentos que vão repercutir na visão de língua do senso comum, nas práticas de formação docente e no ensino da língua portuguesa. Escamoteia-se, assim, o fato de que as palavras, como as orações, só existem em situação concreta de comunicação discursiva e, consequentemente, elimina-se a possibilidade de resposta ativa nessa comunicação (BAKHTIN, 2003).

Ainda no plano do ensino, percebe-se o aproveitamento da discussão para a inculcação de um ideal de língua legítima, priyilégio de poucos, ao tempo que se desenvolve uma "intimidação", definida por Bourdieu (1996, p. 38) como "violência simbólica que não se mostra enquanto tal por não implicar eventualmente qualquer ato de intimidação" [grifo do autor]. Essa intimidação simbólica faz com que professores e alunos se sintam aquém de um patamar linguístico reservado a poucos e contribui para o lucro desses poucos, através das diversas formas de comercializar produtos que visam a "informar" (no sentido empregado por Certeau, 1996) o público "leigo" que desconhece a própria língua: artigos em jornais e revistas, livros, palestras e conferências, cursos e outros similares.

\section{Considerações finais}

Conclui-se que, analisando o fenômeno numa perspectiva dialógica, várias respostas ativas à proposta do acordo ortográfico são formuladas: as que defendem ou desaprovam a reforma, a partir da mesma perspectiva da língua como tesouro comentada neste trabalho, e as respostas, que como esta minha, questionam essa visão e se instalam no âmbito da crítica ao consenso, à unificação, 
${ }^{9}$ Financiamento do CNPq. enquanto saída para o apagamento das diferenças e inculcação de um modelo legitimado simbólica e economicamente.

Contrapondo-se às forças das instâncias de poder já mencionadas, uma perspectiva de resposta ativa (BAKHTINE/VOLOSCHINOV, 1977; BAKHTINE, 1975; BAKHTIN, 2003) do sujeito pode apontar caminhos para o trabalho efetuado com a língua no ensino em diferentes condições institucionais.

A pesquisa que coordeno, intitulada "Autonomia relativa na produção de textos em diferentes contextos de ensino" , objetiva a reflexão sobre os indícios de compreensão e produção ativas e sobre ações que contribuem para o desenvolvimento de uma autonomia relativa do leitor e produtor de textos em vários contextos de ensino e aprendizagem de línguas, em situação de sala de aula.

Nessa investigação, no que diz respeito ao ensino do português como língua materna, ressalta-se a necessidade de fomentar diversas atividades, com diversos gêneros discursivos, que proporcionem indícios da constituição de uma autonomia relativa do sujeito leitor e produtor de textos orais e escritos.

Essa necessidade de utilização de uma variedade de atividades e gêneros da forma mais ampla possível nas situações de ensino já é objeto de constatação em outras pesquisas. Entretanto, não é a diversidade dos gêneros discursivos e dos textos em si, nem o fato de apresentálas aos alunos, que parece proporcionar algum indício de autonomia relativa, porque fazer isso seria mais uma vez apostar no reconhecimento de formas e sentidos, mesmo que desta vez tendo como base unidades maiores, como o texto e o discurso, em vez da frase. Trata-se, sim, de criar oportunidades para falas vivas no sentido bakhtiniano, o que só poderá se dar dentro de uma visão do ensino de língua materna como espaço de diálogo e não como lugar de prescrição, mesmo que, muitas vezes, essa prescrição não apareça por ser subliminar, por estar escondida na roupagem das "novas" teorias e metodologias. 


\section{Referências}

Acordo Ortográfico da Língua Portuguesa. Disponível em:

http://www.cplp.org. Acesso em: 23 de nov. 2007.

Acordo ortográfico. Disponível em: http://www.

portaldalinguaportuguesa.org. Acesso em: 23 de nov. 2007.

AZEVEDO, R. Restaurar é preciso: reformar não é preciso.

Veja, São Paulo, n. 36, p. 98-99, 12 de set. 2007.

ACHARD, P. Um ideal monolíngüe. In VERMES, G;

BOUTET, J. (Orgs.) Multilingüismo. Campinas: Editora da UNICAMP, 1989.

BAKHTINE, M. Esthétique et théorie du roman. Paris:

Gallimard, 1975.

BAKHTINE, M. /VOLOSCHINOV. Le marxisme et la philosophie du langage. Paris: Les Éditions de Minuit, 1977.

BAKHTIN, M. Estética da criação verbal. São Paulo: Martins Fontes, 2003.

CERTEAU, Michel de; JULIA, Dominique; REVEL, Jacques. Une politique de la langue. Paris: Gallimard, 1975.

CERTEAU, Michel de. A invenção do cotidiano. Artes de Fazer. Petrópolis: Vozes, 1996.

BOURDIEU, Pierre. A economia das trocas lingüisticas. São Paulo: EDUSP, 1996.

DECROSSE, A. Um mito histórico, a língua materna. In VERMES, G.; BOUTET, J. (Orgs.) Multilingüismo. Campinas: Editora da UNICAMP, 1989.

DUCROT, Oswald; SHAEFFER, Jean-Marie. Nouveau dictionnaire encyclopédique des sciences du langage. Paris: Seuil, 1995. 
ECO, Umberto. A busca da língua perfeita na cultura européia. Bauru: EDUSC, 2001.

GALISSON, Robert; COSTE, Daniel. Dictionnaire de Didactique des langues. Paris: Hachette, 1976.

NAVARRO, Silvio; SELIGMAN, Felipe; RABELLO, Maria Luiza. País quer falar bem a língua. Folha de S. Paulo, São Paulo, 24 de nov. 2007

TEIXEIRA, Jerônimo. Riqueza da língua. Veja, São Paulo, n. 36, p. 88-96, 12 de set. 2007.

XAVIER, Carlos Alberto. "Entendimento entre partes". Língua Portuguesa, São Paulo, n. 8, p. 38-41, 2007. Entrevista concedida a BERGEL, Mariana.

ZOZZOLI, Rita Maria Diniz. O processo de constituição de uma gramática do aluno leitor e produtor de textos: a busca de autonomia. Trabalhos em Lingüística Aplicada, n. 33, p. 7-21, 1999.

ZOZZOLI, Rita Maria Diniz. Língua materna e língua estrangeira: o discurso da dominação e o ensino de línguas. In: BRITO, Célia; TEIXEIRA, Elizabeth (Orgs.). Aquisição e ensino-aprendizagem do português. Belém: EDUFPA, 2002. 